\title{
WORKING MEMORY CAPACITY AND LEXICAL DENSITY IN L2 SPEECH PRODUCTION
}

\author{
Janaina Weissheimer ${ }^{1}$ \\ Mailce Borges Mota ${ }^{2}$
}

\begin{abstract}
Resumo: Este estudo investiga a relação entre a capacidade de memória de trabalho e a densidade lexical (DL) no desempenho oral e no desenvolvimento da habilidade de produção oral em L2. Os 45 participantes deste estudo foram submetidos a duas coletas de dados, cada uma consistindo de um teste de amplitude de memória de trabalho durante o desempenho oral, adaptado de Daneman (1991), e de uma tarefa de produção oral em L2, com um intervalo de doze semanas entre elas. A DL foi determinada pela proporção de itens lexicais repetidos e não repetidos na fala dos participantes. Os resultados mostram que a amplitude da memória de trabalho está negativamente relacionada à $D L$ oral em L2, ou seja, os participantes com maior amplitude usaram mais itens lexicais repetidos. Quanto ao desenvolvimento da habilidade oral, apenas os participantes com menor amplitude de memória de trabalho demonstraram um aumento significativo na medida de DL ao longo das duas fases de coleta de dados.
\end{abstract}

Palavras-chave: memória de trabalho; densidade lexical; produção oral; $L 2$

1 Universidade Federal do Rio Grande do Norte

2 Universidade Federal de Santa Catarina/ CNPq

Organon, Porto Alegre, nº 51, julho-dezembro, 2011, p. 267-287 


\section{INTRODUCTION}

Many researchers have claimed that speaking ${ }^{3}$ should be seen and investigated as a skill in its own right (LEVELT, 1989; DEBOT, 1992; BOCK, 1995; BYGATE, 2001a; KORMOS; DÉNES, 2004; KORMOS, 2006). In attempting to unveil the complexities of speech production, it is inevitable to consider the concept of working memory capacity, the system that controls and regulates behavior for performance in cognitive tasks (JUFFS; HARRINGTON, 2011). Research on speech production to date acknowledges the fact that limitations in individuals' working memory capacity may be seen as a possible independent constraint on the process of speaking in both L1 (e.g., DANEMAN; GREEN, 1986; DANEMAN, 1991) and L2 (e.g., FORTKAMP, 1999; HARSUIKER; BARKHUYSEN, 2006; MIZERA, 2006).

Fortkamp (1999) found a significant correlation between an L2 version of the Daneman's (1991) speaking span test and fluency and articulation in L2. In a follow-up study, Fortkamp (2003) found that participants who have larger working memory capacity are also able to produce faster and more continuous speech, as well as use fewer silent pauses. Interestingly, trade-off effects were found between accuracy, complexity and lexical density in this study. That is, more accurate and complex speech was attained only at the expense of the use of frequent lexical items.

Weissheimer and Fortkamp (2004) set out to closer investigate the relationship between working memory capacity and fluency, this time also focusing on an extra variable, namely the role of memory strategy use and practice in working memory capacity. As for the relationship between working memory scores and fluency measures, these researchers found positive and significant correlations, thus reassuring the predictive ability of the speaking span test.

Aiming at investigating the relationship between working memory and L2 speech production, but with the more specific goal of trying to unveil the particularities of spontaneous and planned speech performance, Guará-Tavares (2005) found correlations between working

3 In the present study, 'speaking,' 'speech production' and 'speech performance' are operationalized as the ability to perform orally in an L2 narrative task (FORTKAMP, 2003; D'ELY, 2006). A 'task', in turn, is defined, following Ellis (2003), as a tool devised for teaching, learning, and research purposes, the performance of which allows learners to convey meaning for communicative and/or learning aims. 
memory scores and fluency in spontaneous speech performance, and between working memory scores and accuracy and fluency in planned speech performance. Finardi and Prebianca (2006) aimed at investigating the relationship between working memory capacity and L2 fluency, accuracy, complexity and lexical density in a picture description task. The fact that working memory scores only correlated significantly with the measure of fluency in their study led the researchers to conclude that, to speak fast, participants were left with few resources to enable them to produce accurate, complex and lexically dense speech.

Xhafaj (2006) set out to investigate differences in the distribution of silent pauses in L1 and L2 speech production of Brazilian speakers, trying to disentangle the relationship between pause distribution as an indicator of lack of fluency in L2 speech and working memory capacity. Her results indicate that larger-capacity speakers are better able to sustain L2 fluency (with fewer pauses within boundaries and longer speech runs) than those speakers with fewer resources.

Fortkamp and Bergsleithner (2007) and Bergsleithner (2007) examined how individual differences in working memory capacity relate to L2 learners' noticing and use of a grammatical structure in an L2 oral task. Results in both studies show that individuals with a larger working memory capacity tend to speak more accurately and that opportunities for noticing L2 forms tend to improve accuracy in L2 speech production. The researchers advance the proposal that noticing (Schmidt, 1992) can be indeed a necessary condition for L2 learning to take place. However, learners' ability to notice a grammatical form and later use it in speaking is mediated by their working memory capacity.

Mizera (2006) found a significant correlation between L2 working memory capacity and L2 oral fluency. Kormos and Sáfár (2008) found a significant correlation between phonological short-term memory capacity and the overall proficiency of pre-intermediate learners; and between the digit span test and the L2 acquisition of learners at a beginner's level of proficiency. Finally, Prebianca (2010) showed that bilingual lexical access is predicted by working memory capacity. In her study, higher spans retrieved lexical items faster than lower spans.

Although there has clearly been substantial initiative towards investigating the role of working memory capacity in language production, as shown above, much more systematic research is needed so that the pro-

Organon, Porto Alegre, nº 51, julho-dezembro, 2011, p. 267-287 
cesses of speech production, and the role of working memory in speaking, can be thoroughly understood. With that in mind, this study focuses on scrutinizing the relationship between working memory capacity and lexical density, hoping to shed some new light on the lack of correlations found between these two variables in at least two previously mentioned studies (FORTKAMP, 2003; FINARDI; PREBIANCA, 2006).

In order to contribute to that discussion, the present study focuses on two main objectives: (a) to verify whether and how working memory capacity and lexical density in L2 speech production are related (b), to examine whether the speaking span test is related to the development of L2 lexical density. The ultimate purpose of this study is to contribute to both theories of working memory, in that it further specifies the nature of capacity limits in working memory, and to theories of L2 speech production since it demonstrates the relationship between working memory capacity and lexical density in the development of L2 speech production. Finally, it may provide methodological suggestions for best assessing the relationship between working memory capacity and L2 speech production in the future.

\section{METHOD}

In order to address the relationship between working memory capacity and lexical density in L2 speech production, a longitudinal, experimental, quantitative study was carried out focusing on the following research questions: a) are working memory capacity and lexical density in L2 speech production related?; and b) Do higher and lower span individuals experience different gains in speech production scores, in terms of lexical density, across phases? It is hypothesized, based on research which correlates working memory capacity with higher-order cognitive behavior that participants' working memory capacity scores will positively correlate with measures of L2 lexical density in phases one and two of the experiment and that higher span participants will experience more gains in L2 lexical density scores within tests.

\section{Participants}

Sixty-two undergraduate students of the English course at a university in the northeast of Brazil integrated the original sample of this 
experiment. The cohort consisted of nineteen male and forty-three female participants, ages ranging between 18 and 35, with a mean of 23.5, thus a predominantly adult population. Because participants belonged to different semesters in the course, they were all submitted to a proficiency trial in order to obtain a more homogeneous sample in terms of L2 speaking proficiency ${ }^{4}$. All participants agreed to be volunteers in this study and signed a consent form.

After the proficiency trial, forty-five participants still integrated the cohort and seventeen were excluded from the sample, based on the judgment of three experienced raters ${ }^{5}$. The remaining participants were classified as intermediate-level subjects.

\section{Instruments}

Each phase of the experiment consisted of two tasks: a task aimed at measuring working memory capacity and a task aimed at eliciting speech production in the $\mathrm{L} 2$.

\section{The Speaking Span Test (SSPAN)}

Participants' working memory capacity in this study was assessed by means of the Speaking Span Test, developed by Daneman and Green (1986) and Daneman (1991), which has been traditionally used and has proven to be adequate in various attempts to elicit differences in working memory capacity among individuals and its relation to $\mathrm{L} 2$ speech production (FORTKAMP, 1999, 2000; D’ELY et al., 2005; FINARDI, 2005; FINARDI; PREBIANCA, 2006; GUARÁ-TAVARES, 2006; BERGSLEITHNER, 2007; WEISSHEIMER; MOTA 2009; PREBIANCA, 2010).

To compare working memory span scores in the first phase of the experiment to span scores in the second phase, two versions of Daneman's (1991) speaking span test were constructed with 60 unrelated words each. An additional training test was developed with other 60

4 The proficiency trial consisted of a speech generation task which participants performed in the first phase of the experiment. Three experienced raters assessed participants' speech samples using a Speaking Proficiency Scale (adapted from the Cambridge FCE Oral Assessment Scale). Participants' overall speech production was assessed in terms of fluency, accuracy and discourse management.

5 Pearson's Correlations, which were run for each of the three ratings in the proficiency trial, proved to be significant $\mathrm{r}(52)=.59 ; .76$; and $.64, \mathrm{p}<.01$, showing consistency among results provided by the three different raters. Cronbach's coefficient alpha for the proficiency test was .85 , attesting internal consistency and reliability to the test, and, therefore, confirming the intermediate level of proficiency of the participants involved in the study. 
unrelated words and used in both phases of the data collection as demonstration and practice before each actual test took place.

Following Daneman (1991), the total number of 60 words was organized in three sets, each of 2, 3, 4, 5 and 6 words. Each word was presented individually, in the middle of a computer screen for one second. Participants were instructed to read the words silently. After ten milliseconds, the next word in the set appeared in the same position on the screen as the previous word was presented. After each participant finished generating the sentences for a given set, the next set would appear, and this procedure was followed until all sets had been presented. A two-word set was presented first, followed by a three-word set, and so on, ending the sequence with a six-word set. The end of each set was signaled by a black screen with interrogation marks on it and a sound signal. The interrogation marks signaled the number of words that had to be recalled and the number of sentences to be produced in that specific set. Participants were instructed to use the words in the correct form and order they appeared to generate syntactically and semantically acceptable sentences, aloud, in English.

Participants' speaking span was defined as the maximum number of words (out of 60) for which they could generate grammatically and semantically acceptable sentences in English. Following Daneman (1991) and Daneman and Green (1986), in this study, participants' responses, which were recorded, transcribed and analyzed, generated two different speaking span scores: a speaking span strict score and a speaking span lenient score. In the speaking span strict score, as in Daneman (1991) and Daneman and Green (1986), one point was given to the sentences the subject produced containing the target word in the exact form and order of presentation. In the speaking span lenient score, similarly to Daneman (1991) and Daneman and Green (1986), one point was also given to sentences that contained the target word in a form other than that of presentation (e.g., target word being 'drug' and the word in the sentence produced being 'drugs'). However, differently from Daneman (1991) and Daneman and Green (1986), half a point was also awarded in the lenient score to: (a) sentences containing certain grammatical inaccuracies (article "the", prepositions or third person " $\mathrm{s}$ ") 6 , and (b)

6 According to Ellis (1987) and Butler (2002), these specific mistakes - article "the", prepositions and third person "s"- among others, are very persistent mistakes for learners of English as a second language and their acquisition, when at all mastered, happens towards very late stages of interlanguage. 
words recalled in an order other than that of presentation. No credit was given to ungrammatical sentences in terms of syntax and semantics (except for those three cases described above).

Half of the participants performed first the SSPAN 1 and the other half performed first the SSPAN 2 in both phases of the experiment in order to avoid order and task effects. The interval between testing phases was of twelve weeks.

\section{The Speech Generation Task (SGT)}

Participants' L2 speech production was assessed by means of two Speech Generation Tasks, which elicited scores of lexical density for each of the subjects involved in the data collection. The two speech generation tasks (one for phase one and the other for phase two of this experiment) consisted of participants describing two picture-cued narratives and were administered right after participants had completed the memory tests in both phases.

Participants were encouraged to narrate the stories with as many details as possible, using their own imagination, command of language and background knowledge to accomplish the task. No time limit was given to participants for performing the task and they could keep the picture in front of them during the narration. All participants took at least one minute to perform the task. Task effects were controlled for; that is, half of the participants narrated story 1 and the other half narrated another 2 in the first phase, and the pattern was inversed in the second data collection phase.

Following Mehnert (1998), O'Loughlin (1995), Fortkamp (2000) and D'Ely (2006), lexical density of L2 speech was measured by weighted lexical density. Lexical density refers to the proportion of new and repeated words in a text (O'Loughlin, 1995). Weighted lexical density is a more complete measure, which provides a relationship between the number of words produced with lexical properties and the number of words produced with grammatical properties (O'LOUGHLIN, 1995).

According to O'Loughlin (1995), in order to assess participants' weighted lexical density, it is first necessary to determine what a basic unit of lexical density is. For this purpose, he sug- 
gests that the notion of a "linguistic item" rather than the "word" is more appropriate to analyze lexical density in speech data, because there is not a one-to-one correspondence between linguistic items and words in English (O'LOUGHLIN, 1995; FORTKAMP, 2003; D'ELY, 2006). Consequently, multiword verbs (i.e. fall in love with), phrasal verbs (look for), idioms (head over hills) and contracted forms (I'm, aren't), which consist of more than one word, are counted as one linguistic item in the present study.

Following Fortkamp (2000) and D'Ely (2006), under the category of grammatical items were included: (1) all modals and auxiliaries, (2) all determiners (articles, demonstrative, possessive adjectives, quantifiers and numerals). (3) all pronouns, and 'this' and 'that' when used to replace clauses, (4) interrogative adverbs (what, when, how) and negative adverbs (not, never), (5) all contractions of pronouns and auxiliary verbs (counted as one item), (6) all prepositions and conjunctions, (7) all discourse markers including conjunctions (but, so, and), sequencers (next, finally), particles (oh, well), lexicalized clauses (you know, I mean) and quantifier phrases (anyway, somehow, whatever), (8) all lexical filled pauses (so, well), (9) all interjections (gosh, really, oh) and (1) all reactive tokens (OK, No!).

Under the lexical category (FORTKAMP, 2003; D'ELY, 2006) nouns, adjectives, verbs, adverbs of time, manner and place were considered lexical items. As the notion of item rather than word is used here, multiword verbs, idioms and contractions (both of pronouns and main verbs) counted as one lexical item.

As a subsequent step to the analysis, lexical and grammatical items were divided into high-frequency and low-frequency lexical and grammatical items. High and low frequency lexical and grammatical items were determined in relation to their idiosyncratic use in each participant's speech samples(s). Thus, a high frequency grammatical or lexical item was considered the one which appeared more than once in the same speech sample. Inflections and derivations of the same lexical or 
grammatical item, which denote repetition, were counted as a high frequency item (i.e. fall/fell, this/these). A low frequency item was considered the one which appeared only once in the same speech sample. Subsequently, high-frequency items were assigned half the weight of low frequency items. This is a more refined analysis which is warranted in formal investigations of lexical density (O'LOUGHLIN, 1995; MEHNERT, 1998; FORTKAMP, 2003; D’ELY 2006).

As a final step to the analysis, in order to obtain an index of participants' weighted lexical density in the participants' narratives, the total number of weighted lexical items was determined, following O'Loughlin (1995), Fortkamp (2000), and D'Ely (2006). All lexical and grammatical items were counted and highfrequency items were given half of the weight of low-frequency lexical and grammatical items. So a score was obtained for both lexical and grammatical items. The sum of both scores resulted in the total number of weighted linguistic items. The score obtained from the weighted lexical items was divided by the total number of weighted linguistic items. The resulting figure was then multiplied by 100 to determine the percentage of weighted lexical items over the total number of weighted linguistic items in each participants' speech sample(s).

\section{RESULTS AND DISCUSSION}

Working memory capacity and the ability to produce lexically dense L2 speech

The main objective of this study was to further investigate the counter-intuitive evidence between span scores and weighted lexical density, found in Fortkamp (2000) and Finardi and Prebianca (2006). The initial hypothesis in those and this study was that working memory scores would correlate positively with measures of L2 weighted lexical density, in terms of the percentage of weighted (low-frequency) lexical items over the total number 
of linguistic items produced by the participants. In other words, it was predicted that higher span participants would be able to produce a higher range of vocabulary items, thus repeating fewer items than lower span participants. In this sense, they would have a greater amount of low-frequency items present in their speech as compared to lower span individuals.

However, results in Table 1 show the exact opposite direction of the one described above. As one can see, although not reaching significance and showing a weak relationship, results of working memory and lexical density show, in general, an opposite pattern from the one expected $(\mathrm{r}(45)=-.10$ and $-.13, \mathrm{p}>.05)$ for strict and lenient scores, respectively, in the first phase of the study, and ( $\mathrm{r}$ $(45)=-.12$ and $-.11, \mathrm{p}<.05)$ for strict and lenient scores, respectively, in the second phase.

\section{Table 1}

Correlations between working memory capacity scores and weighted lexical density including all participants in the two phases.

\begin{tabular}{|c|c|c|c|}
\hline & WLD 1 & & WLD 2 \\
\hline WM1S & -.10 & WM2S & -.12 \\
\hline WM1L & -.13 & WM2L & -.11 \\
\hline
\end{tabular}

$\mathrm{N}=45$

$\mathrm{WLD}=$ weighted lexical density

WMS $=$ working memory strict

$\mathrm{WML}=$ working memory lenient

As depicted in Figure 1, contrary to what was expected, a negative correlation was approached, meaning that, as working memory scores increased among participants, the number of low-frequency lexical items they produced slightly decreased. In other words, participants with a higher working memory capacity in this study tended to use a greater number of high-frequency lexical items in their speech. 


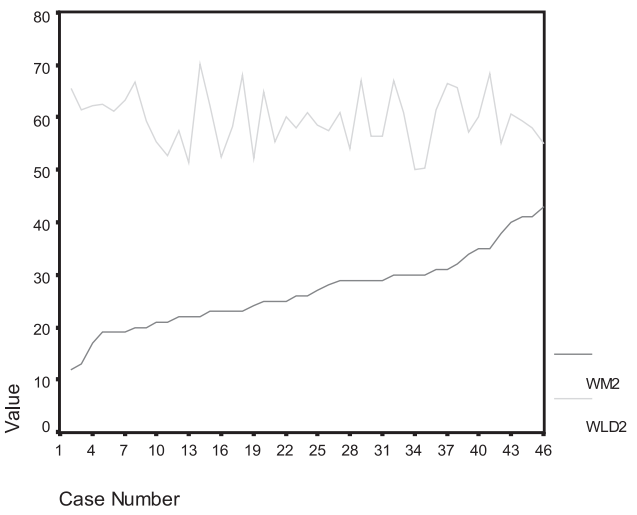

Figure 1. Participants' performance in the speaking span test and measures of weighted lexical density in the speech generation task.

The results regarding the relationship between working memory and weighted lexical density reported above are similar to those in Fortkamp (2000) and Finardi and Prebianca (2006), where the same pattern of relationship was observed.

Fortkamp (2000) found that individuals with a higher working memory capacity tend to produce speech with lower lexical density; that is, they use a smaller number of different lexical items when speaking in the L2. In attempting to explain this counter-intuitive finding in her study, she claims that the lower lexical density in participants' speech samples might be related to the fact that L2 speech production is lexically driven and speakers tend to re-use those lexical items that are already activated so that resources can be directed at other aspects of the production process.

Similarly, Finardi and Prebianca (2006) have also reported a negative relation of working memory and lexical density. Once again, they offer trade-off effects among different aspects of speech production as an explanation to account for such negative correlation. According to these researchers, because L2 processes seem to posit an extra load on the speakers' cognitive system and because they possess a limited working memory capacity, it is li- 
kely that when aiming at speaking more fluently and using more complex structures, L2 speakers seem to penalize other aspects of the skill, in this case, lexical density.

Taking together the results in Fortkamp (2000), Finardi and Prebianca (2006) and in this study, there appears to exist an association between working memory capacity and weighted lexical density, but this association (although weak) indicates that, in fact, individuals with a larger working memory capacity tend to use a smaller number of different lexical items. As a result, there seems to be room to claim that the relationship between working memory capacity and weighted lexical density in L2 seems to be negatively driven.

However a question still remains: why do higher span individuals produce fewer low-frequency lexical items than lower span ones? It may be that, as argued by Fortkamp (2000), by using more high-frequency lexical items, in other words, by using repeated words more frequently in the speech generation task, higher span individuals are able to allocate more working memory resources to generate more accurate speech and to increase fluency by pausing less when speaking.

A closer look at our data reveals that high frequency lexical items in higher span individuals' speech seem to be composed of formulaic language ${ }^{7}$ and ready-made chunks of language, among other items. These items, which may be called islands of reliability (DECHERT, 1983), seem to serve as an economy heuristic (ANDERSON, 1995) in the speech of higher span individuals, ensuring more fluent speech production.

The suggestion that the use of formulaic language might help L2 speakers to produce fluent stretches of speech is not new. Dechert (1983) coined the term islands of reliability which, similarly to formulaic language, represent "native-like utterances consisting of formula-like linguistic units of varying length and syntactic complexity, which serve as anchoring points for further planning and execution speech processes"

7 Formulaic language consists of lexical chunks that result from binding frequent collocations (Ellis, 2002) 
(p.183). In terms of the speech processes, the use of formulaic language is believed to make language processing more automatized, which frees more cognitive space for other aspects of speech production.

Contemporary studies in the speech production area have devoted increasing attention to the analysis of formulaic speech (KORMOS; DÉNES, 2004). Towell, Hawkins, and Bazergui (1996) investigated what qualitative changes take place in the use of formulaic language parallel to the increase of fluency after participants spent a year in the target language environment. They found that the participants improved in how they employed different types of formulae after their study abroad. Similarly, Ejzenberg (2000) compared how fluent and non-fluent speakers employ formulaic language. Her results also showed that fluent students were able to make use of prefabricated chunks more efficiently, whereas non-fluent learners frequently used formulae inappropriately.

To illustrate this discussion, we compare a higher span individual's speech sample to a lower span individual's one in an attempt to identify potential islands of reliability which may account for the increase in fluency:

\section{Participant 33 (higher span):}

Ok the story there it goes the there is a couple in a restaurant and they are just having their dinner and so on but the woman was like talking a lot bla bla bla and the man was like oh my god what can I do I'm just here sitting and doing anything and she's talking a lot a lot a lot bla bla bla so then he just started to think on hitting her and he just thought I can break this bottle of wine in her in her head or better I can bite her nose oh no I can just kick her her head I don't know but I have to do something I'm so bored here and she's talking a lot bla bla bla how silly he got something and threw on her nose she was like what did you do why did you do that and he was just eating his meal and so on and she said this is not polite and he just was just there eating and that's it finish

\section{Weighted lexical density: $\mathbf{5 1 , 4 0}$ Speech rate unpruned: 147,94 Silent pauses per minute: $\mathbf{0 , 0 0}$}

\section{Participant 32 (lower span):}

Well, the story is very sad. A man, he's begging for a woman his pardon, he wants to marry her, but she don't care...she doesn't care about him. 
She ...he brings her many presents: a ring, necklace, brilliant, you know, many presents...many gifts to her. But she doesn't care. She doesn't want anything with him, she doesn't want to mary him. And he does many impossible stuffs for her to pay attention him, to marry him, because he loves her too much. But anything he does calls her attention. So, in the end, as he sees that anything he does it will be necessary to change her mind, or to change her mood, so he appears in front of her house with another girl, and...in a beautiful and big new car, to make her impressed. So this case, finally, she feels that she has lost him to another woman and that's the end of the story. I guess it's good for him, not for her because she's alone and she has....and he has another company, another affair to be with him as long as it lasts.

\section{Weighted lexical density: 64,34 \\ Speech rate unpruned: 75,00 \\ Silent pauses per minute:7,24}

It is possible to observe in the two samples above that the higher span participant seems to employ a greater amount of formulaic language and ready-made chunks (and so on, bla bla bla, that's it, I don't know, like), and to repeat him/herself more. The lower span individual, conversely, does not seem to make such great use of formulaic language, and seems to repeat him/herself less, which is reflected in their higher score of weighted lexical density.

The fact that higher span individuals use formulaic language and tend to repeat these items corroborates Fortkamp's (2000) claims that higher span individuals tend to re-use already activated items. According to Ashcraft (1994) and Ellis (2002), words that are used more frequently are stored more strongly in memory (mental lexicon), and stronger memory traces can easily yield faster search times. As a result, higher span individuals are able to faster access high frequency words, increasing their speech rate and having to pause less. On the long run, higher span individuals seem to keep benefiting from the frequency effect, once, as argued in Ellis (2002), language acquisition is a process of dynamic emergence and learners' language is a product of their history of usage. 
The relationship between working memory capacity and lexical density in the development of $\mathrm{L} 2$ speech

Concerning the role of the SSPAN in predicting L2 speech development, this study predicted more gains in terms of lexical density to higher span individuals than lower span ones across testing phases. Surprisingly, higher span individuals produced fewer low-frequency lexical items from phase one to phase two, whereas lower span individuals increased the number of low-frequency items produced in their second speech generation task $(M=60,17$ to $M=59,80$, for the higher group, and $M=59,30$ to $M=61,18$, for the lower group).

Differently from what had been hypothesized, only lower span individuals in this study showed gains in terms of lexical density, considering the two phases of the experiment, with an increase in the number of low-frequency items produced in their second speech generation task in relation to the first one as one can see in Table $2^{8}$.

Table 2

Paired-samples T- tests for measures of L2 speech production for each

\begin{tabular}{|c|c|c|c|c|c|c|c|}
\hline \multicolumn{8}{|c|}{ memory group } \\
\hline & & & \multicolumn{3}{|c|}{ Paired Differences } & \multirow[b]{2}{*}{$d f$} & \multirow[b]{2}{*}{ Sig(2-tailed) } \\
\hline & & & Mean & Std. Deviation & T & & \\
\hline \multicolumn{8}{|c|}{ WM_GRUPO } \\
\hline \multicolumn{8}{|l|}{ Lower } \\
\hline & Pair & WLD1 - WLD2 & $-1,87$ & 2,96 & $-2,53$ & 15 & 0,02 \\
\hline \multicolumn{8}{|l|}{ Higher } \\
\hline & Pair & WLD1 - WLD2 &, 37 & 4,78 &, 32 & 17 & 0,74 \\
\hline
\end{tabular}

All in all, it seems reasonable to think, based on what has been said, that the development of L2 speech in higher and lower span individuals, in terms of lexical density, seems to be sensitive to different aspects. While lower span individuals' speech seems to be characterized by the use of low-frequency words and less repetition, higher span individuals' speech seems to reflect: the use of high-frequency words, more

8 As it has been well established in the literature (CROOKES, 1991), in order attest significance, $\mathrm{p}$ values, displayed in the right column of the table above, have to be lower than $.05(\mathrm{p}<.05)$. Taking this into consideration, only gains in L2 weighted lexical density among lower span participants $(\mathrm{t}(15)=1.88, \mathrm{p}=0.02)$ can be considered statistically significant. 
repetitions of lexical items and the elaboration of more complex structures. For both cases, there are advantages and disadvantages. The use of low-frequency words by lower span individuals results in more dense speech but also in slower lexical searches and, consequently, reduced fluency. The use of high-frequency words by higher span individuals, on the other hand, allows them to speak more fluently, accurately and elaborately, but makes their speech sound more repetitive.

\section{FINAL CONSIDERATIONS}

The present study focused on verifying whether and how working memory capacity and lexical density in L 2 speech production are related, and to examine whether the speaking span test is related to the development of $\mathrm{L} 2$ lexical density.

To pursue the research questions in this study, forty-five intermediate learners of English as an L2 were submitted to two data collection phases, each one consisting of a working memory test (SSPAN) and a speech generation task (a picture-cued narrative), with a twelve-week interval between the two data collections. Participants' speaking sam-

ples were analyzed in terms of weighted lexical density (percentage of low-frequency items over linguistic items).

The results, in general terms, show that higher span individuals seem to produce speech which is, in general, less lexically dense, i.e. it contains fewer low-frequency lexical items and more lexical repetitions, in comparison to the one of lower span individuals. These results regarding L2 speech production seem to support the existence of competing goals in speech performance (fluency, accuracy, complexity and lexical density), reported by several researchers in the speech production field (FOSTER; SKEHAN, 1996; SKEHAN; FOSTER, 1995; BYGATE 2001; FORTKAMP, 2003; D' ELY et al. 2004; FINARDI 2005; GUARÁ-TAVARES 2006; FINARDI; PREBIANCA 2006; XHAFAJ 2006; FORTKAMP; BERGSLEITHNER, 2007; and BERGSLEITHNER, 2007; WEISSHEIMER; MOTA, 2009). Trade-offs between these speech production goals may explain the fact that, in this study, higher span individuals are generally more fluent while speaking the L2, but, conversely, they repeat themselves more and are less able to produce lexically-dense speech than lower span ones.

Organon, Porto Alegre, nº 51, julho-dezembro, 2011, p. 267-287 
As for the development of lexical density in L2 speech production, the speaking span test in this study was able to inversely predict measures of lexical density both in the performance and in the development of speech. Lower span individuals did not only use more low-frequency items in the beginning of the experiment, but also increased their rate of low-frequency items throughout the two phases. Higher span individuals, on the contrary, seemed to have relied a greater deal on high-frequency words in both phases of the experiment to prioritize, as said before, other aspects of speech production, such as fluency, accuracy or complexity.

The present study represents a tentative and preliminary attempt to systematically examine the relationship between working memory capacity and lexical density in L2 speech. Although it has been theoretically and methodologically based on existing literature in the field, this work has limitations. First of all, the reduced sample size of the two span groups involved in this study may have been responsible for the weakening of some correlations and the lack of significance of gains in performance. Moreover, weighted lexical density, as it was applied in this study, measures the frequency in which items appear in the learners' speech samples. It taxes repetitions of items, but repetitions are devices that bring cohesion to discourse, and also function as emphatic devices. Weighted lexical density does not account for different degrees of complexity in speakers' lexical choices. Consequently, a careful analysis of how repeated items are used in participants' speech and the inclusion of a lexical measure which tackles differences in complexity of lexical items should be considered in the future.

Despite the noted limitations, the proposals made in the present study are relevant since they go beyond the general notion that working memory is an efficient predictor of L2 speech performance. This study represents a step forward, by showing how working memory capacity is involved in L2 speech development. The results reported in this study also have implications for understanding the nature of capacity limits in working memory. All in all, our goal in this experimental study was not to resolve these issues, but to demonstrate the importance of working memory capacity in the development of L2 speech production. There is still a lot to be done in this field. 


\section{REFERENCES}

ASHCRAFT, Mark. Human memory and cognition. New York: Harper Collins, 1994.

FORTKAMP, Mailce B. M. ; BERGSLEITHNER, Joara M. The relationship among working memory capacity, noticing, and L2 speech production. Revista Signo, v. 32, p. 40-53, 2007.

BERGSLEITHNER, Joara M. The relationship among individual differences in working memory capacity, noticing, and L2 speech production. Doctoral Dissertation. Universidade Federal de Santa Catarina, 2007.

BOCK, Kathryn. Sentence Production: From Mind to Mouth. In Miller, J.L. and Eimar, P.D. (Eds). Speech, language and communication. San Diego: Academic Press. p.p. 181-216, 1995.

BUTLER, Yuko.G. Second language learners' theories on the use of English articles. SSLA, 24, 451-480, 2002.

BYGATE, Mike. Speaking. In R. Carter and D. Nunan (Eds.), The Cambridge guide to teaching English to speakers of other languages (pp. 14-20). Cambridge: Cambridge University Press, 2001.

CROOKES, Graham. Second language speech production research: a methodologically-oriented review. Studies in Second Language Acquisition, 13, 113-132, 1991.

DANEMAN, Meredyth; GREEN, I. Individual differences in comprehending and producing words in context. Journal of Memory and Language, 25, 1-18, 1986.

DANEMAN, Meredyth. Working memory as a predictor of verbal fluency. Journal of Psycholinguistic Research, 20, 445-464, 1991.

DECHERT, Hans.W. How a story is done in a second language. In C. Faerch and G. Kasper (Eds.), Strategies in interlanguage communication (pp 175-195). London: Longman, 1983.

D'ELY, Raquel. A focus on learners' metacognitive processes: the impact of strategic planning, repetition, strategic planning plus repetition, and strategic planning for repetition on L2 oral performance. Unpublished doctoral dissertation. Universidade Federal de Santa Catarina, 2006. De BOT, Kees. A bilingual production model: Levelt's speaking model adapted. Applied Linguistics, 13, pp. 1-24, 1992. 
EJZENBERG, Roseli. The juggling act of oral fluency: A psycho-sociolinguistic metaphor. In: Riggenbach, H. (Ed.), Perspectives on fluency. The University of Michigan Press, Michigan, pp. 287-314, 2000.

ELLIS, Nick. Reflections on frequency effects in language processing. Studies in Second Language Acquisition,24, 143-188, 2002.

ELLIS, Rod. Interlanguage variability in narrative discourse: Style shifting in the use of the past tense. Studies in Second Language Acquisition, 9, pp. 12-20, 1987.

FINARDI, Kyria. R. Individual differences in working memory capacity and complexity of L2 speech production of learners exposed to the planning for repetition condition. Unpublished research paper. Universidade Federal de Santa Catarina, Florianópolis, 2005.

FINARDI, Kyria.R. and PREBIANCA, Gicele. Working memory capacity and speech production in L2: evidence from a picture description task. Revista de estudos da linguagem, v.14, n.1, 231-260, 2006. FINARDI, Kyria; WEISSHEIMER, Janaina. On the Relationship between working memory capacity and L2 speech development. Signotica (UFG), v. 20, p. 367-391, 2009.

FONTANINI, Ingrid; WEISSHEIMER, Janaina; BERGSLEITHNER, Joara; PERUCCI, Margareth; D’ELY, Raquel. Working memory capacity and L2 skill performance. Revista brasileira de Lingüística Aplicada, 5,(2), 189-230. Belo Horizonte, 2005.

FORTKAMP, Mailce B..M. Working memory capacity and aspects of L2 speech production. Communication and Cognition, v. 32, p. 259296, 1999.

FORTKAMP, Mailce. B. M. Working memory capacity and L2 speech production: an exploratory study. Tese de doutorado. Florianópolis: Pós-Graduação em Inglês e Literatura Correspondente, UFSC, 2000. FORTKAMP, Mailce. B. M. Working memory capacity and fluency, accuracy, complexity, and lexical density in L2 speech production. Fragmentos, 24, 69-104, 2003.

FOSTER, Pauline; SKEHAN, Peter. The influence of planning and task type on second Language performance. Studies in Second language acquisition, 18, 299-323, 1996.

GUARÁ-TAVARES, Maria da Glória. Working memory, pre-task planning and L2 speech production. Unpublished research paper. Universidade Federal de Santa Catarina, 2005. 
GUARÁ-TAVARES, Maria da Glória. Planning, Working memory capacity and L2 speech performance. Unpublished doctoral research paper. Universidade Federal de Santa Catarina, 2006.

HARTSUIKER, Rob; BARKHUYSEN, P. Language production and working memory: The case of subject-verb agreement. Language and Cognitive Processes, 21, 181- 204, 2006.

JUFFS, Alan; HARRINGTON, Michael. Aspects of working memory in L2 learning. Language Teaching. v. 44 n. 2, p. 137-166, 2011.

KORMOS, Judit; DÉNES, Mariann. (2004). Exploring measures and perceptions of fluency in the speech of second language learners. System, 32, 145-164, 2004.

KORMOS, Judit. Speech production and second language acquisition. Hillsdale, N.J.:Erlbaum, 2006.

KORMOS, Judit; Sáfár, Anna. Phonological short-term memory, working memory and foreign language performance in intensive language learning.Bilingualism: Language and Cognition, 11, 261-271, 2008.

LEVELT, Willem. J. M. Speaking: From intention to articulation. Cambridge, Massachusetts: The MIT Press. Chapters 1-2, 1989.

MEHNERT, Uta. The effects of different lengths of time for planning on second language performance. Studies in Second Language Acquisition, 20, pp. 83-108, 1998.

MENDONÇA, Daniela Working memory capacity and the retention of L2 vocabulary. Unpublished Master's Thesis, Universidade Federal de Santa Catarina, Florianópolis, 2003.

MIZERA, Gregory. J. Working memory and L2 oral fluency. Unpublished doctoral dissertation, University of Pittsburgh, 2006.

O'LOUGHLIN, Kieran. Lexical density in candidate output on direct and semi-direct versions of an oral proficiency test. Language Testing, 12, 217-237, 1995.

PREBIANCA, Gicele V. V. Working memory capacity and foreign language speech production: a look at lexical access processes and level of proficiency. Saarbrücken, Germany: Lambert Academic Publishing. 234 p, 2010. SCHMIDT, Richard. Psychological mechanisms underlying second language fluency. Cambridge: Cambridge University Press, 1992.

SKEHAN, Peter. and Foster, Pauline. Task type and task processing as influences on foreign language performance. In Skehan, P. (Ed) Working papers in English Language Teaching, 3, pp. 139-188, 1995. 
TOWELL, Richard, Hawkins, Roger, and Bazergui, N. The development of fluency in advanced learners of English. Applied Linguistics, 17, 84-119, 1996.

WEISSHEIMER, Janaina; Fortkamp, Mailce B.M. The effects of practice and strategy use on L2 working memory capacity and fluency. Unpublished research paper. Universidade Federal de Santa Catarina, Florianópolis, 2004.

WEISSHEIMER, Janaina ; MOTA, Mailce B. Individual Differences in Working Memory Capacity and the Development of L2 Speech Production. Issues in Applied Linguistics, v. 17, p. 34-52, 2009.

XHAFAJ, Donesca C.P. Pause distribution and working memory capacity in L2 speech production. Unpublished Master's Thesis. Universidade Federal de Santa Catarina, Florianópolis, 2006. 